\title{
MORPHOLOGICAL VARIATION AND ALLOMETRY OF THE BACULUM IN STOATS, MUSTELA ERMINEA (CARNIVORA, MUSTELIDAE) FROM WESTERN CARPATHIANS
}

\author{
Alexander Csanády* and Anna Onderková \\ Institute of Biology and Ecology, Faculty of Science, P. J. Šafárik University \\ Šrobárova 2, SK-054 41 Košice, Slovakia, ${ }^{*} E-m a i l:$ alexander.canady@gmail.com
}

In this study we investigated allometry and variation in the baculum of the stoat Mustela erminea and compared it with head-and-body length not involved in reproduction. The stoat is a species with pre-copulatory selection (manifested by the high degree of malebiased sexual size dimorphism) therefore we predicted that baculum allometry may be isometric or exhibited negative allometry. We also test the hypothesis that the baculum size is positively correlated with adult body size and may be used as a reliable indicator of male good condition. Results presented in this study were different according to which regression model type was used. While the OLS slope for baculum length in M. erminea indicated negative allometry, the RMA model showed positive allometry. The results obtained for M. erminea weren't in agreement with mentioned hypothesis that if baculum allometry is affected by the degree of pre-copulatory selection relative to post-copulatory selection, then we predict isometry or negative allometry of the baculum. Nevertheless, we suggest, that to confirm the above statements further analysis of more numerous material of $M$. erminea coupled with comparative analysis of testicular growth studies are needed to fully understand the importance and function of the baculum relative to the mating system.

Keywords: variability, allometry, Mustela erminea, os penis, museum collection.

\section{INTRODUCTION}

The baculum is a heterotopic bone in the penis that occurs in males of all species of Carnivora, including the Mustelidae (Aвramov 2002, BARrshNikov et al. 2003, Miller \& Nagorsen 2008, Malecha et al. 2009, KrawczyK et al. 2011, Schulte-Hostedde et al. 2011, Vercillo \& Ragni 2011). Morphology of the mustelid baculum has been described in several studies (BURT 1960, van Soest \& van Bree 1970, King \& Moody 1982, Grue \& King 1984, BaryshNikov \& Abramov 1997, 1998, Abramov \& Baryshnikov 2000, Baryshnikov et al. 2003, Elsasser \& PARKer 2008, Ruette et al. 2015, ČAnády \& Onderková $2016 a, b)$, which show that this bone tends to be rather simple in structure but with some more complex projections at the tip. A multi-male mating system occurs in many species of Mustelidae (LARIVIÉRE \& JenNings 2009), so the baculum may be under strong sexual selection. If so, there may be a limit to baculum growth (Miller et al. 1998, 1999, 2000, Oosthuizen \& Miller 2000, Miller \& Burton 2001, Miller \& Nagorsen 2008, Kinahan et al. 2008). 
Several authors (Dixon 1995, Miller \& Burton 2001, Miller \& NagorSen 2008, Demuth et al. 2009) showed that females of many mammalian species select mates in part during intromission and evaluate attributes of the penis that are informative about a male's size or other characteristics. Accordingly, if females can benefit by mating with large males and can estimate size of males by size of penis, then positive allometry of penile size relative to body size and small residuals in allometric regression may evolve. Sexually selected traits often show positive allometry and exhibit high phenotypic variation as a result of directional sexual selection (LüPold et al. 2004). Deмuth et al. (2009) and КRАWCZYK et al. (2011) confirmed that the males in better condition have bigger bacula which confirms that this bone is potentially a good indicator of viability and quality in males. On the other hand, reproductive behaviour and mating system are very important for the evolution of penis size (MILLER et al. 1998, 1999, 2000, Oosthuizen \& Miller 2000, Miller \& Burton 2001, FERGUSON \& Lariviére 2004, RAMm 2007). In contrast, according to KinAhan et al. (2008) and Schulte-Hostedde et al. (2011), baculum allometry may be isometric or exhibit negative allometry in species with pre-copulatory selection.

Morphological variability of the baculum in the stoat, Mustela erminea, has not been investigated. We studied a sample from the Western Carpathians. Our study contributes to the knowledge of quantitative characteristics of bacular size and variation. We also investigated the allometry in the baculum in relation to head-and-body length. Stoats exhibit substantial sexual-size dimorphism, with males being larger than females (LARIviéRE \& JenNings 2009). Therefore if bacula allometry is affected by the degree of pre-copulatory selection relative to post-copulatory selection, then we predict isometry or negative allometry of bacular size.

\section{MATERIAL AND METHODS}

Bacula used in this study are in the collection of the Department of Natural History of Šariš Museum, Bardejov. All specimens were collected by T. Weisz, a former curator of museum, as well all individuals were hunting from several localities near the town of Bardejov, i.e., from one small area in north-eastern Slovakia, $\left(49^{\circ} 17^{\prime} \mathrm{N}, 21^{\circ} 17^{\prime} \mathrm{E}\right.$, Slovak Carpathians) in the years 1959-1969. Additional information was obtained from the catalogue and protocol cards associated with the specimens (see Hromada et al. 2015). Small penis bones (from young) individuals and damaged specimens; damage during preparation or storage were excluded and only data obtained from adult males were used for evaluation $(n=23)$. Specimens were assigned to the age class adult based on baculum weight (i.e. exceeding $0.03 \mathrm{~g}$ ) and baculum protuberance (i.e. the presence of protuberance in adult individuals) (van Soest \& van Bree 1970, King \& Moody 1982, Grue \& King 1984, Elsasser \& PARKER 2008).

Bacular length was measured to $\pm 0.01 \mathrm{~mm}$ with a digital calliper, and mass was weighed with a digital balance to $\pm 0.01 \mathrm{~g}$. All bacula were measured according to ČANÁDY 2013, ČANÁdy and Čomor 2013, 2015, ČANÁdy and Onderková 2016a, $b$. The measurements 

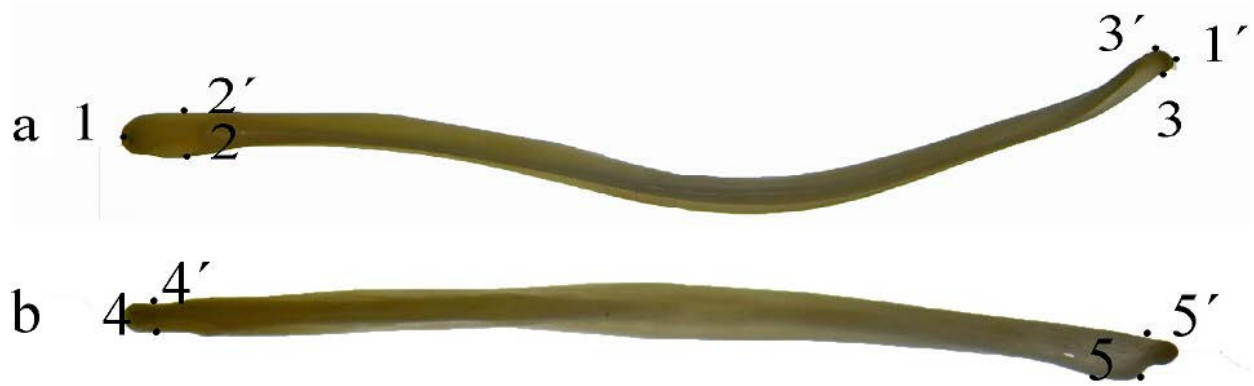

Fig. 1. Baculum measures of Mustela erminea used in the study. Lateral (a), dorsal (b) views. All abbreviations of measures: LeBa (1-1'), DvThp (2-2'), DvThd (3-3'), LtLtThp (4-4'), LtLtThd $\left(5-5^{\prime}\right)$ are explained in Material and methods

collected are described in Figure 1a-b and they include: LeBa - baculum length (1-1'), DvThp - dorsoventral thickness of proximal end (2-2'), DvThd - dorsoventral thickness of distal end (3-3'), LtLtThp - laterolateral thickness of proximal end (4-4'), LtLtThd - laterolateral thickness of distal end (5-5') and finally the $\mathrm{WeBa}-$ baculum weight.

The obtained dataset (untransformed data) was evaluated using the following statistical parameters: minimum and maximum (min-max), mean $(\mathrm{M})$, standard deviation (SD), standard error of the mean (SE) and coefficient of variation (CV). Normal distribution was tested by the three normality tests (the Kolmogorov-Smirnov test, the D'AgostinoPearson omnibus $K^{2}$ test and the Shapiro-Wilk $W$-test). Morphometric variation was examined by means of multivariate method (Principal component analysis - PCA). Correlations between the baculum measurements and head-and-body length were analysed using the Pearson correlation coefficient $\left(r_{p}\right)$. Moreover, multiple significance tests with using Bonferroni's correction were performed on correlations among bacular variables in order to the critical $p<0.05$ can be adjusted to $p<0.001$. Before allometry analysis, measurements were $\log _{10}$ transformed to reduce intra-sample variation and to improve normality. We investigated allometric (log-log) relationships in two steps (Schulte-Hostedde et al. 2011). First, ordinary least squares regression (OLS) was used to determine whether slopes differed from zero. If slopes were significant, we proceeded by using reduced major axis regression (RMA) to test for deviations from isometry.

All analyses were performed using MS Excel 2003 for Windows XP and the statistical analysis system GraphPad Prism, version 5.01 (GraphPad Software, Inc., San Diego, California, USA). Ordinary least square (OLS) regression and reduced axis major (RMA) regressions were evaluated by using the program PAST version $2.17 \mathrm{~b}$ (HAMmER et al. 2001).

\section{RESULTS}

The results of descriptive statistics of the studied baculum variables are presented in Table 1. Result confirmed that the baculum weight together with the proximal parts of bacula were more variables $(\mathrm{CV}>25 \%)$ in part because of low measurement accuracy, while the baculum length $(\mathrm{CV}=5.1 \%)$ and distal parts were the less variable $(\mathrm{CV}<15 \%)$.

The analyses presented in this study showed a strong correlation of the bacular variables between each other and bacular variables between the head- 
Table 1. Descriptive statistics of head-and-body length (HBL) and six baculum traits of stoats, Mustela erminea. Legend: $\mathrm{N}$ - number; min-max - range margins; $\mathrm{M}$ - mean; SD - standard deviation; SE - standard error of the mean, CV - coefficient of variance. All abbreviations of baculum measures are explained in Material and methods. Data are given in $\mathrm{mm}$.

\begin{tabular}{lccccc}
\hline Measured traits & $\mathrm{N}$ & min-max & $\mathrm{M} \pm \mathrm{SD}$ & $\mathrm{SE}$ & $\mathrm{CV}$ \\
\hline HBL & 21 & $262.00-289.00$ & $276.3 \pm 8.06$ & 1.76 & 2.9 \\
LeBa & 23 & $22.83-27.12$ & $25.23 \pm 1.30$ & 0.27 & 5.1 \\
DvThp & 23 & $0.84-2.47$ & $1.76 \pm 0.52$ & 0.11 & 29.5 \\
LtLtThp & 23 & $0.64-2.05$ & $1.31 \pm 0.38$ & 0.08 & 29.0 \\
DvThd & 23 & $1.09-1.94$ & $1.44 \pm 0.21$ & 0.04 & 14.4 \\
LtLtThd & 23 & $0.95-1.40$ & $1.16 \pm 0.12$ & 0.02 & 10.0 \\
WeBa & 23 & $0.03-0.07$ & $0.04 \pm 0.01$ & 0.00 & 27.7 \\
\hline
\end{tabular}

and-body length (Table 2), but mainly for the baculum weight (WeBa) with bacular length (LeBa), dorsoventral (DvThp) and laterolateral (LtLtThp) thickness in proximal part. Similar, strong correlation was between baculum length and proximal parts of the baculum. Moreover, all of them were still strongly significant $(p<0.01$ and/or $p<0.001)$ after Bonferroni correction for multiple comparisons.

The results of PCA showed that the first two principal components (PC1PC2) explain $87.3 \%$ of the variation. The first principal component (PC1) explained $76.6 \%$ of the total variance and was correlated mainly with dorsoventral thickness of proximal end (DvThp, $r=0.67$ ), laterolateral thickness of proximal end (LtLtThp, $r=0.62$ ) and baculum weight (WeBa $r=0.40$ ). The second factor (PC2) accounted for only $10.7 \%$ and was positive correlated with baculum weight $(\mathrm{WeBa}, \mathrm{r}=0.90)$ and negatively with laterolateral thickness of proximal end (LtLtThp, $r=-0.33$ ).

Summary results for our OLS and RMA analyses are shown in (Table 3, Fig. 2) and were depending on the regression model used. OLS regression

Table 2. Summary of Pearson's correlations $\left(r_{s}\right)$ between bacular and head-and-body length for a collection of stoats, Mustela erminea in Slovakia. All abbreviations of baculum measures are explained in Material and methods. The correlations are shown with the significant levels ${ }^{*} \mathrm{p}<0.05$ and ${ }^{* * *} \mathrm{p}<0.001$ are signed.

\begin{tabular}{lcccccc}
\hline & LeBa & DvThp & LtLtThp & DvThd & LtLtThd & WeBa \\
\hline DvThp & $0.49^{*}$ & & & & & \\
LtLtThp & $0.47^{*}$ & $0.93^{* * *}$ & & & & \\
DvThd & 0.05 & 0.00 & 0.09 & & & \\
LtLtThd & 0.12 & 0.20 & 0.17 & 0.45 & & \\
WeBa & $0.59^{* * *}$ & $0.63^{* * *}$ & $0.65^{* * *}$ & 0.10 & 0.04 & \\
HBL & $0.52^{*}$ & 0.23 & 0.05 & 0.06 & 0.25 & 0.22 \\
\hline
\end{tabular}




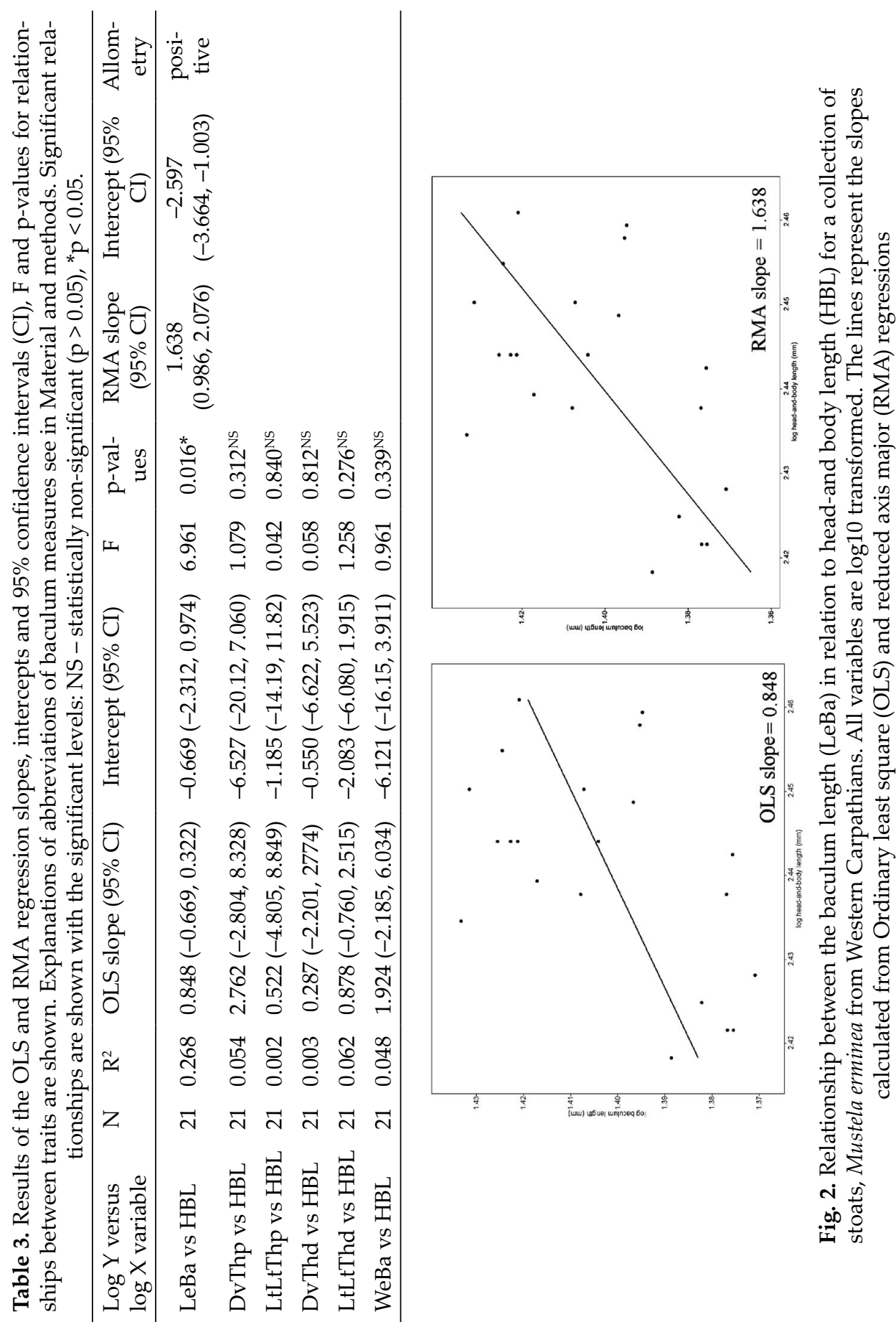


indicated and confirmed linear and relatively weak relationship between baculum length and head-and-body length. Result showed that the M. erminea baculum exhibited negative allometry, but this was in sharp contrast to RMA slope estimates, which indicated positive allometry for the baculum (Table 3 ).

\section{DISCUSSION}

The baculum grows throughout life (KRAWCZYK et al. 2011) and therefore this growth is connected with the energetic cost and is connected with the risk of infection or breakage. Therefore, baculum may play a role as indicator for a good physical condition of the male (Lariviére \& Ferguson 2002). It is very significant, because bacular size is strongly correlated with body size, so could be informative about a male's absolute or relative size during copulation (Miller \& Nagorsen 2008). Moreover, several authors (e.g. De Marinis 1995, Miller \& Burton 2001, Lüpold et al. 2004, Kinahan et al. 2008, KrawcZYK et al. 2011) showed that the largest and heaviest males were favoured by sexual selection as breeders. The bone size served as a reliable indicator of good genes to female mates during breeding (KRAWCZYK et al. 2011). In our previous studies of the baculum in carnivores from Western Carpathians were proved that bacular length was generally less variable than other thickness measurements (ČAnÁdy 2013, ČAnÁdy \& Čomor 2013, 2015, ČanÁdy \& ONDERKová $2016 a, b)$. This may be due to the ease of measurement (measurement error), because length measurements are basically error-free. Similar results were obtained for several species of family Mustelidae, i.e. for Mustela nivalis (ČANÁdY \& Onderková 2016a), Martes foina (Čanády \& Onderková 2016b) and Martes martes (unpubl. data). Similar analysis in this study confirmed that the bacular length was well correlated with head-and-body length. Positive correlations between the bacular dimensions between each other as well with the baculum weight confirmed their relationship to provide mechanical support during copulation and interact more directly with the female reproductive tract (BARYSHNikov et al. 2003, ČANÁdy 2013, ČANÁdy \& Čomor 2013, 2015, ČANÁdy \& ONDERKoví 2016a, b).

Reutte et al. (2015) proved sexual size dimorphism in favour of males for both species (Martes martes and M. foina) for somatic measures. For baculum length they showed bigger values for stone marten ( $M$. foina) opposite to pine marten (M. martes). In species with pre-copulatory selection, the baculum should exhibit isometry or negative allometry together with shallower allometric slopes (Kinahan et al. 2008). In contrast, for two species (Martes americana and M. pennanti) with male-biased sexual size dimorphism was showed different results depending on the regression model used (Schulte-Hostedde et al. 2011). These results were not consistent with other studies of mammals 
that implicate sexual selection as an important factor in explaining variation in baculum morphology (Miller et al. 1999, Miller \& Burton 2001, LüPOLD et al. 2004, Kinahan et al. 2007, TasiKas et al. 2007, YurkowsKi et al. 2011). Authors assumed that stabilizing selection rather than sexual selection was the evolutionary force shaping variation in baculum length because allometric slopes were less than one (using the OLS regression model). They assumed that this pattern occurs because post-copulatory selection plays a smaller role than pre-copulatory selection.

Results presented in this study were different according to which regression model type was used. While the OLS slope for baculum length in $M$. erminea indicated negative allometry, the RMA model showed positive allometry. Our results were in accordance with data obtained by Schulte-HostedDE et al. (2011) for Martes americana. Moreover, our results were different for both species; Mustela erminea (showed in this study) and M. nivalis (ČANÁDY \& ONDERKOVÁ 2016a). While RMA slopes indicated positive allometry for $M$. erminea, for $M$. nivalis was confirmed negative allometry. The results obtained for M. erminea weren't in agreement with hypothesis that if baculum allometry is affected by the degree of pre-copulatory selection relative to post-copulatory selection, then we predict isometry or negative allometry of the baculum. In contrast, the negative allometry and relative weak relationship between baculum length and head-and-body length in M. nivalis are consistent with prediction that the baculum is under stabilizing selection (Schulte-Hostedde et al. 2011) for an optimal baculum size. These discrepancies in allometry between both species were similar showed by Schulte-Hostedde et al. (2011), for two carnivores of the family Mustelidae, Martes americana and M. pennanti. Nevertheless, it should be noted, that these differences may be coupled with sample size. The small sample size in M. erminea evaluated in this study $(\mathrm{n}=$ 23) opposite to bigger size in M. nivalis $(\mathrm{n}=277)$.

The present results add new information about morphometric variation in baculum of Mustela erminea from Western Carpathians. The results weren't in agreement with hypothesis therefore we suggest, that to confirm the above statements further analysis of more numerous material of M. erminea coupled with comparative analysis of testicular growth studies are needed to fully understand the importance and function of the baculum relative to the mating system.

Acknowledgements - We would like to express my sincere thanks to Tomáš Jászay, head of the Natural History Department of Šariš Museum, Bardejov, Slovakia, for granting access to the collections and for the general help provided. Our thanks also go to anony- 
mous referees for their valuable comments on the manuscript. Finally, we would like to thank David McLean for revising the English language.

\section{REFERENCES}

Abramov, A. V. (2002): Variation of the baculum structure of the Palearctic badger (Carnivora, Mustelidae, Meles). - Russian Journal of Theriology 1: 57-60.

Abramov, A. V. \& Baryshnikov, G. F. (2000): Geographic variation and intraspecific taxonomy of weasel Mustela nivalis (Carnivora, Mustelidae). - Zoosystematica Rossica 8: 365-402.

Baryshnikov, G. F. \& Abramov, A. V. (1997): Structure of baculum (os penis) in Mustelidae (Mammalia, Carnivora), Communication 1. - Zoologicheskii Zhurnal 76: 1399-1410.

Baryshnikov, G. F. \& Abramov, A.V. (1998): Structure of baculum (os penis) in Mustelidae (Mammalia, Carnivora), Communication 2. - Zoologicheskii Zhurnal 77: 231-236.

Baryshnikov, G. F., Bininda-Emonds, O. R. P. \& Abramov, A. V. (2003): Morphological variability and evolution of the baculum (os penis) in Mustelidae (Carnivora). - Journal of Mammalogy 84: 673-690. https://doi.org/10.1644/1545-1542(2003)084<0673:MVA EOT>2.0.CO;2

Burt, W. H. (1960): Bacula of North American mammals. - Miscellaneous Publications, Museum of Zoology, University of Michigan 113: 1-76 +25 plates.

ČAnÁDy, A. (2013): Variability of the baculum in the red fox (Vulpes vulpes) from Slovakia. - Zoology and Ecology 23: 165-170. https://doi.org/10.1080/21658005.2013.832848

ČAnÁDy, A. \& Čomor, L. (2013): Contribution to knowledge of the variability of the penis bone (baculum) in the Eurasian wolf (Canis lupus) from Slovakia. - Lynx (Praha) n.s. 44: 5-12.

ČAnÁdy, A. \& Čomor, L. (2015): Allometry of the baculum in the wolf (Canis lupus, Canidae) as an indicator of viability and quality in males. - Zoology and Ecology 25: 192-198. https://doi.org/10.1080/21658005.2015.1044164

ČANÁDy, A. \& ONDERKová, A. (2016a): Are size, variability and allometry of the baculum in relation to body length signals of a good condition in male weasels Mustela nivalis. Zoologischer Anzeiger 264: 29-33. https://doi.org/10.1016/j.jcz.2016.07.003

ČAnÁdy, A. \& ONDERKová, A. (2016b): Notes on variation in the baculum of Martes foina from Czech Silesia, Czech Republic (Carnivora: Mustelidae). - Lynx (Praha) n.s. 47: $45-50$.

Elsasser, S. C. \& Parker, G. H. (2008): Morphometric criteria for distinguishing species and age-cohorts of Ermine (Mustela erminea) and long-tailed weasel (M. frenata). Acta Zoologica Academiae Scientiarum Hungaricae 54: 75-88.

Grue, H. E. \& KING, C. M. (1984): Evaluation of age criteria in New Zealand stoats (Mustela erminea) of known age. - New Zealand Journal of Zoology 11: 437-443. https://doi.org/ 10.1080/03014223.1984.10428258

Demuth, J., Hromada, M., KrawczyK, A., Malecha, A., Tobolka, M. \& Tryjanowski, P. (2009): Cranial lesions caused by helminth parasites and morphological traits in the European polecat Mustela putorius. - Helminthologia 46: 85-89. https://doi. org/10.2478/s11687-009-0017-8

De Marinis, A. M. (1995): Craniometric variability of polecat Mustela putorius L. 1758 from North-Central Italy. - Hystrix, Italian Journal of Mammalogy (n.s.) 7: 57-68. https://doi.org/10.4404/hystrix-7.1-2-4053 
Dixson, A. F. (1995): Baculum length and copulatory behaviour in carnivores and pinnipeds (Grand Order Ferae). - Journal of Zoology 235: 67-76. https://doi.org/10.1111/ j.1469-7998.1995.tb05128.x

Ferguson, S. H. \& Lariviére, S. (2004): Are long penis bones an adaption to high latitude snowy environments? - Oikos 105: 255-267. https://doi.org/10.1111/j.00301299.2004.13173.x

Hammer, Ø., Harper, D. A. T. \& Ryan, P. D. (2001): PAST: Paleontological statistics software package for education and data analysis. - Palaeontologia Electronica 4: 1-9.

Hromada, M., Čanády, A., Mikula, P., Peterson, A. T. \& Tryjanowski, P. (2015): Old natural history collections for new millennium - birds and mammals in the collection of PhMr. Tibor Weisz in Sarisske Museum Bardejov, Slovakia. - Folia Oecologica. Acta Universitatis Presoviensis 7: 115-141.

Kinahan, A. A., Bennett, N. C., Belton, L. E. \& Bateman, P. W. (2008): Do mating strategies determine genital allometry in African mole rats (Bathyergidae). - Journal of Zoology 274: 312-317. https://doi.org/10.1111/j.1469-7998.2007.00386.x

KInG, C. M. \& Moody, J. E. (1982): The biology of the stoat (Mustela erminea) in the National Parks of New Zealand III. Morphometric variation in relation to growth, geographical distribution, and colonisation. - New Zealand Journal of Zoology 9: 81-102. https://doi.org/10.1080/03014223.1982.10423839

KrawczyK, A. J., Malecha, A. W. \& Tryjanowski, P. (2011): Is baculum size dependent on the condition of males in the polecat Mustela putorius? - Folia Zoologica 60: 247-252.

LARIVIÉRE, S. \& Ferguson, S. H. (2002): On the evolution of the mammalian baculum: vaginal friction, prolonged intromission or induced ovulation? - Mammal Review 32: 283294. https://doi.org/10.1046/j.1365-2907.2002.00112.x

Lariviére, S. \& Jennings, A. P. (2009): Family Mustelidae (weasels and relatives). Pp. 564656 In: Wilson D. E. \& Mittermeier R. A. (eds): Handbook of the mammals of the World. Vol. 1. Carnivores. - Lynx Edicions, Barcelona.

Lüpold, S., McElligott, A. G. \& Hosken, D. J. (2004): Bat genitalia: allometry, variation and good genes. - Biological Journal of the Linnean Society 83: 497-507. https://doi. org/10.1111/j.1095-8312.2004.00407.x

Malecha, A. W., KrawczyK, A. J. \& Hromada, M. (2009): Morphological variability of baculum (os penis) in the polecat Mustela putorius. - Acta Zoologica Cracoviensia 52: 115-120. https://doi.org/10.3409/azc.52a_1-2.115-120

Miller, E. H. \& Burton, L. E. (2001): It's all relative: allometry and variation in the baculum (os penis) of the harp seal, Pagophilus groenlandicus (Carnivora: Phocidae). - Biological Journal of the Linnean Society 72: 345-355. https://doi.org/10.1111/j.1095-8312.2001. tb01322.x

Miller, E. H. \& Nagorsen, D. W. (2008): Bacular variation and allometry in the western marten Martes caurina. - Acta Theriologica 53: 129-142. https://doi.org/10.1007/ BF03194246

Miller, E. H., Stewart, A. R. J. \& Stenson, G. B. (1998): Baculum and testicle growth, allometry, and variation in the harp seal (Pagophilus groenlandicus). - Journal of Mammalogy 79: 502-513. https://doi.org/10.2307/1382981

Miller, E. H., Jones, I. L. \& Stenson, G. B. (1999): Baculum and testes of the hooded seal (Cystophora cristata): growth and size-scaling and their relationships to sexual selection. - Canadian Journal of Zoology 77: 470-479. https://doi.org/10.1139/z98-233

Miller, E. H., Pitcher, K. W. \& Loughlin, T. R. (2000): Bacular size, growth and allometry in the largest extant Otariid, the Steller Sea Lion (Eumetopias jubatus). - Journal of 
Mammalogy 81: 134-144. https://doi.org/10.1644/1545-1542(2000)081<0134:BSGAAI> 2.0.CO;2

Oosthuizen, W. H. \& Miller, E. H. (2000): Bacular and testicular growth and allometry in the Cape fur seal Arctocephalus p. pusillus (Otariidae). - Marine Mammal Science 16(1): 124-140. https://doi.org/10.1111/j.1748-7692.2000.tb00908.x

Ramm, S. A. (2007): Sexual selection and genital evolution in mammals: a phylogenetic analysis of baculum length. - The American Naturalist 169: 360-369. https://doi. org/10.1086/510688

Ruette, S., Larroque, J., Albaret, M., Vandel, J. M. \& Devillard, S. (2015). Quantifying the age-and sex-dependent morphological variation in two syntopic mustelids: Martes martes and Martes foina. Mammalian Biology - Zeitschrift für Säugetierkunde 80: 414-423. https://doi.org/10.1016/j.mambio.2015.06.001

Schulte-Hostedde, A., Bowman, J. \& Middel, K. R. (2011): Allometry of the baculum and sexual size dimorphism in American martens and fishers (Mammalia: Mustelidae). - Biological Journal of the Linnean Society 104(4): 955-963. https://doi.org/10.1111/j.10958312.2011.01775.x

Schwery, O., Köhnemann, B. A., Michler, F. U. \& Brinkmann, W. (2011): Morphometrical characterisation of a raccoon (Procyon lotor L.) population from Müritz National Park (Germany) by means of the os baculum. - Beiträge zur Jagd-und Wildforschung 36: 605-617.

Tasikas, D. E., Fairn, E. R., Laurence, S. \& Schulte-Hostedde, A. I. (2009): Baculum variation and allometry in the muskrat (Ondatra zibethicus): a case for sexual selection. - Evolutionary Ecology 23: 223-232. https://doi.org/10.1007/s10682-007-9216-2

Vercillo, F. \& Ragni, B. (2011): Morphometric discrimination between Martes martes and Martes foina in Italy: the use of the baculum. - Hystrix, Italian Journal of Mammalogy (n.s.) 22: 325-331. https://doi.org/10.4404/hystrix-22.2-4669

van Soest, R. W. M. \& van Bree, P. J. H. (1970): Sex and age composition of a stoat population (Mustela erminea Linnaeus, 1758) from a coastal dune region of the Netherlands. - Beaufortia 17: 51-77.

Yurkowski, D. J., Chambellant, M. \& Ferguson, S. H. (2011): Bacular and testicular growth and allometry in the ringed seal (Pusa hispida): evidence of polygyny? - Journal of Mammalogy 92(4): 803-810. https://doi.org/10.1644/10-MAMM-A-082.1

Received July 7, 2016, accepted March 16, 2017, published March 30, 2018 